This paper is part of the Proceedings of the $3^{\text {rd }}$ International Conference on Design,

\title{
The concept of using energy generated by water flowing in pipes to power devices monitoring the water supply network
}

\author{
B. Kowalska ${ }^{1}$, D. Kowalski ${ }^{1}$, M. Kwietniewski ${ }^{2}$ \& J. Rak ${ }^{3}$ \\ ${ }^{1}$ Faculty of Environmental Engineering, \\ Lublin University of Technology, Poland \\ ${ }^{2}$ Faculty of Building Services, Hydro and Environmental Engineering, \\ Warsaw University of Technology, Poland \\ ${ }^{3}$ Faculty of Civil and Environmental Engineering and Architecture, \\ Rzeszów University of Technology, Poland
}

\begin{abstract}
Converting energy from drinking water flowing in the pipes into electricity has become a new direction of development of innovative technologies in the field of environmental engineering. Currently, many different devices designed for this purpose are available on the market. There are water turbines, integrated with generators, placed within transit pipelines or pumps designed to allow the driving of the rotor stream of flowing water. These pumps generate a current in the electric motors integrated with various types of pressure reducers equipped with microturbines. However, the possibility of practical application of the electricity produced in this way is still little known or limited.

The aim of the paper is to present the possibility of energy utilization generated by drinking water as it flows through turbines integrated into pipes to power measuring devices for monitoring water networks. Presented concepts have been reserved in Polish patents.

Keywords: water supply, energy recovery, microturbines.
\end{abstract}

\section{Introduction}

One of the major components of a water supply system's operating costs are electricity costs [1]. Electrical energy is mainly consumed by the pump units [2]. 
Therefore, a number of solutions have been implemented to optimize the operation of pumping stations of different levels [3, 4]. In addition to optimization of the pump unit selection, optimized systems for their control have been developed as well [5]. Any other options for reducing electricity costs currently appear to be offered beyond the pumping stations - in water treatment plants and water distribution networks [6].

One of the primary ways of reducing volume of electricity costs is the use of alternative methods for obtaining electricity [7]. Wind power stations and photovoltaic power stations have been used to this end. A seawater desalination plant in Gran Canaria, Spain may serve as an example [8]. Wind turbines applied there power the pumps which drive seawater to the plant located about $50 \mathrm{~m}$ higher. The initial stage of the desalination process involves generation of high pressure (40 bar) which at subsequent stages of the process becomes unnecessary. Thus produced excessive pressure is therefore used by a system of microturbines driving the remaining process pumps working at the plant premises. Another solution to reduce electricity costs is recovery of the energy using turbines and microturbines located outside the pumping stations, within the transmission and distribution pipelines. Pioneer solutions in this field were applied in transit water pipes located in mountain areas. Water turbines with integrated electric generators were inserted into the pipes. Water flowing down by gravitation from pipeline components located higher, drives the installed turbines and consequently, generates electricity. The Ourem, Portugal solution or the Cracow, Poland solution may serve as an example [5,9]. Turbines installed in such pipes operate at relatively high and stable flow rates. Reduction of the flowing water pressure connected with such operation depends on the difference in the levels of the front and end of the pipe, which may be significant in mountain areas.

A much more challenging task has been the recovery of energy using microturbines installed within distribution pipes of water supply networks. The basic limitation to their use are pressure reduction values permissible at a given site. This reduction cannot threaten the demanded volume of water supplied to consumers. Another problem is the fluctuating, within an extensive range, flow rates through the microturbines, depending on the actual water consumption by the consumers. At low flow rates (night time and off-peak hours), microturbine efficiency decreases. Designs of new, high-performance turbines respond to these problems [10]. However, even if they are applied, the volume of recovered energy is relatively low. The use of microturbines in the aforementioned pipes is therefore focused to a larger extent on pressure reduction in the determined pipes, rather than on energy recovery. This reduction is primarily aimed at restricting leakage and limiting the number of network pipe and fitting failures [11-13], which consequently leads to reduced network maintenance costs [14]. Recovery of the energy previously consumed during driving of transmitted water related to this reduction, is a kind of extra effect in addition to benefits resulting from pressure reduction.

Minor electricity volumes obtained via microturbines installed within the distribution networks may be used to power the sensors of the network monitoring system. According to the authors, this however requires a comprehensive approach 
to the question of recovering energy from the water stream transmitted via the distribution network. Such approach cannot focus on the microturbines only. A number of problems related to their use need to be solved as well. The aim of the paper is to present the comprehensive concept of self-developed, original technical solutions enabling implementation of this task - the power supply system for monitoring devices, a microturbine integrated with electric generator and a system enhancing temporary flow rates via the turbine.

\section{The concept of powering the monitoring devices}

The question of electricity recovery in water supply networks may be combined with network monitoring systems. Some monitoring devices need to be powered with electricity supplied from the network. This requires the construction of proper power terminals, which increases costs, makes the investment process more complicated and consequently, often leads to abandoning the localization of such devices. This applies in particular to network sections situated in rural areas and far away from the city centres. As a solution to this problem, the authors have proposed a system based on a water microturbine inserted into the distribution or main pipe, with integrated electric generator and a control and electricity storage module. Schematic diagram for this system is presented in Fig. 1.

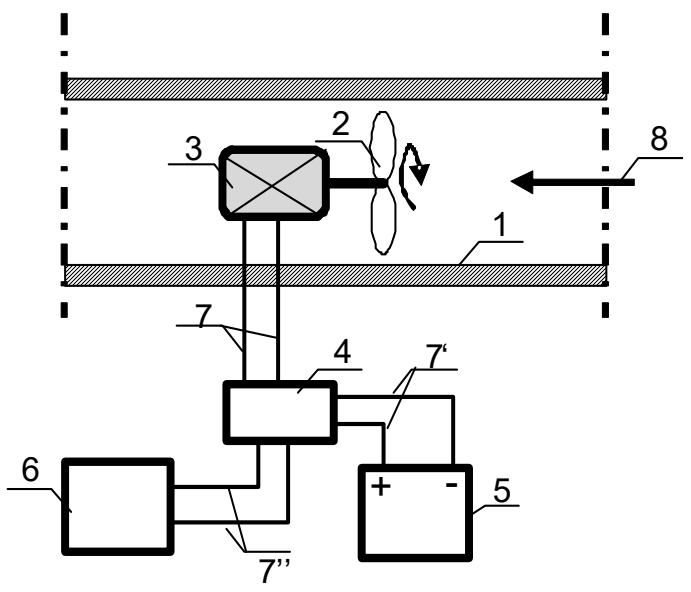

Figure 1: Schematic diagram of the system for powering the monitoring device with energy recovered from water stream transmitted via water pipeline [15]. 1 - pipeline wall, 2 - microturbine, 3 - electric generator, 4 - electronic controller, 5 - rechargeable cell, 6 - powered monitoring device, 7 - electric cables, 8 - recommended water flow direction.

In the above solution, the monitoring device may be powered directly from the electric generator or via the rechargeable cell, depending on the actual microturbine efficiency. The proposed system corresponds to systems used in 
wind power plants. A question should be asked however, what are the potential consequences of turbine rotor blade failure/disability. Pressure reduction appearing in the system in such conditions may exceed the permissible value. To prevent it, the authors suggest to by-pass the microturbine, enabling water flow in case the value is exceeded. The bypass should be equipped with a self-opening valve triggered after permissible difference in the pressure before and behind the microturbine is exceeded. In the concept presented in Fig. 2, the authors proposed a system of two integrated safety valves.

Opening of safety valves installed in the bypass depends on whether valve setting pressure is exceeded. Depending on the direction of flow in the transmission pipes, the upper or bottom valve opens. This significantly reduces the negative effects of microturbine block for the transport of water.

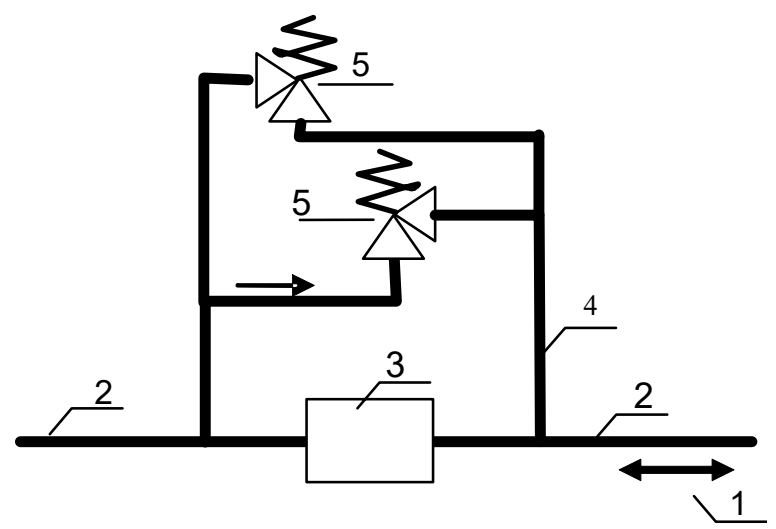

Figure 2: Schematic diagram of microturbine bypass, using two integrated safety valves [16]. 1 - possible water flow directions, 2 - transmission pipeline, 3 - microturbine, 4 - bypass, 5 - safety valve.

\section{The concept of the microtubine}

Another problem to be solved emerging during the installation of microturbines in the pipes of a water distribution system, is the need to apply complex, geometric systems of pipes, which often involves extra costs related to construction of larger water wells [10]. Microtubines must be additionally connected to electric generators. The use of various couplings may lead to reduced power efficiency of the entire system. As a solution to the aforesaid problems, the authors suggested a system in which microturbine rotor, made using permanent magnets, is at the same time the rotor of the electric generator. In the proposed solution, the winding of the electric generator is placed directly in microturbine case walls. Rotating permanent magnets induce electric current in the winding, transmitted to the receiver. A schematic diagram for the system is presented in Fig. 3. 


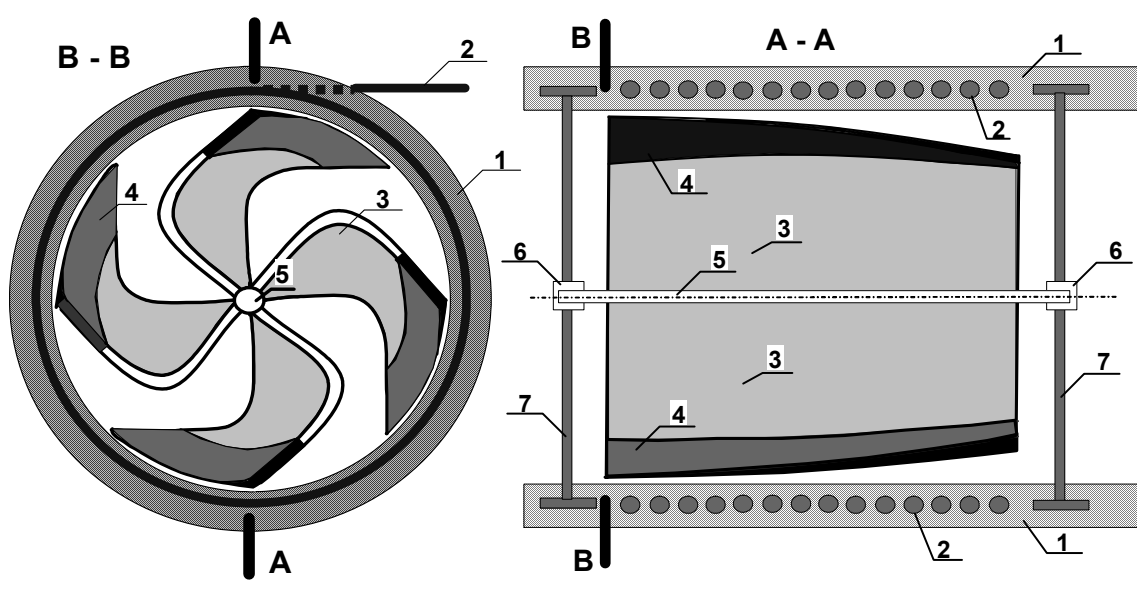

Figure 3: Schematic diagram for the proposed microturbine integrated with electric generator [17]. 1 - case wall, 2 - winding cables, 3 - rotor blades, 4 - permanent magnets, 5 - rotor axis, 6 - bearings, 7 - fixing bars.

\section{The concept of the system enhancing temporary water flow rates via the microturbine}

As mentioned above, one of the basic problems related to operation of microturbines installed within pipes of the water distribution system, is emergence of low water flow rates - at night and during off-peak hours. At low flow rates, there is a risk of failure to reach the start-up thresholds and consequently, no ability to recover energy from the passing water stream. A solution to this problem may be the use of air-water tanks integrated with the microturbine. Schematic diagram for the system is presented in Fig. 4.

Under conditions presented in Fig. 4, water will flow through the turbine periodically - during filling of the air-water tank. This will make it possible to obtain microturbine rotor speed exceeding the electric generator start-up threshold, even in case of low water demand. However, the need to use the cut-off valve proves to be a problem, as its status (open/closed) depends on the level to which the air-water tank is filled up. This valve may be electrically controlled, which questions however the sense of using the energy recovery system. As a solution to this problem, the authors suggested to use a mechanically-driven valve, selfopening or self-closing depending on pressure differences (and related filling up of the air-water tank) in the supplying and discharging pipes. Schematic diagram for this valve is presented in Fig. 5. 


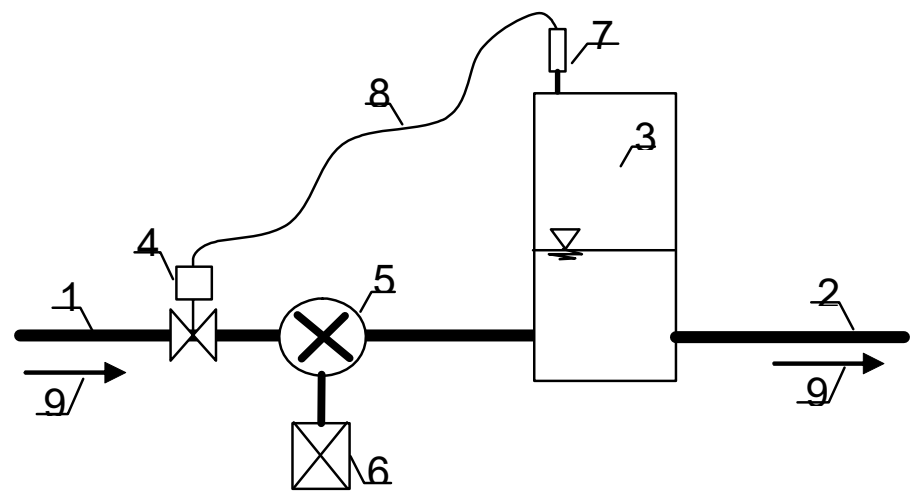

Figure 4: Schematic diagram for the microturbine - air-water tank system [18]. 1 - pipe supplying water with higher pressure, 2 - pipe discharging water with reduced pressure, 3 - air-water tank, 4 - cut-off valve, 5 microturbine, 6 - electric generator, 7 - pressure pick-up, 8 - electric cable, 9 - direction of water flow.

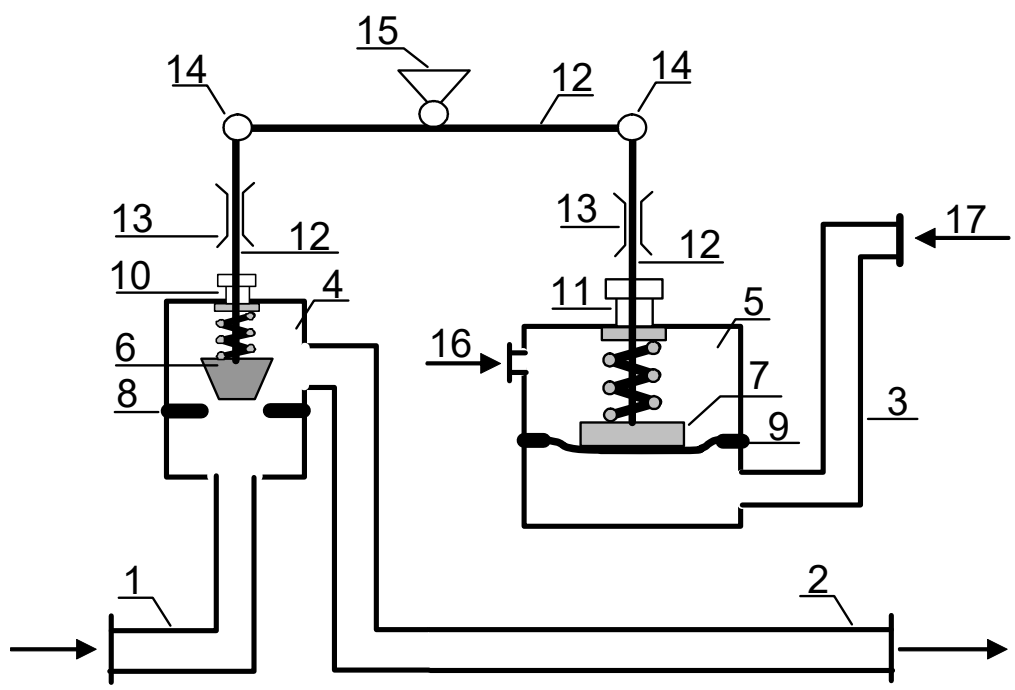

Figure 5: A diagram of a self-acting control valve, cooperating with the proposed system [19]. 1 -supplying pipe, 2 - discharging pipe, 3 pressure conduit, 4 - cut-off valve, 5 - control valve, 6 - valve head, 7 - valve head, 8 - seat, 9 - membrane, 10 - compression spring, 11 - compression spring, 12 - bar, 13 - slideways, 14 - joint, 15 non-sliding support, 16 - air conduit, 17 - pipe transporting water from the water supply system. 


\section{Summary}

The question of energy recovery from water stream transmitted within water supply systems has become an increasingly popular topic. Apart from large turbines with relatively large diameters installed in transit pipes, there have started to appear solutions to be used in the case of smaller distribution pipes. Electricity obtained with their assistance may be used to power the monitoring devices (sensors).

The problem of using microturbines installed within the pipes of the water distribution system should, according to the authors, be solved in a comprehensive manner. This requires consideration of a number of issues, such as: development of a power supply system, taking of corrective actions in case of microturbine block, designing of an optimum microturbine structure (with reduced number of moving components) and enabling operation of the $\mathrm{a} / \mathrm{m}$ energy recovery system at flow rates not exceeding the start-up prerequisites for the microturbines and electric generators.

The collection of concepts presented in the paper is the initial attempt to solve all the aforementioned problems. Advantages of the proposed solutions include simple design, reduced number of moving components of the turbine-electric generator system and no need to use electricity in controlling the water flow process.

Solutions presented in the paper have still not been put into practice. The authors are looking for partners interested in construction of device prototypes, who after verification in laboratory and semi-industrial conditions would be willing to try to implement them in real-life network systems.

\section{Acknowledgement}

This paper was financed by statutory activity of the Faculty of Environmental Engineering, Lublin University of Technology.

\section{References}

[1] Souza E.V., Covas D.I.C. \& Soares A. K., Towards the improvement of the efficiency in water resources and energy use in water supply systems. Proc. of the Tenth International Conference on Computing and Control in the Water Industry, Sheffield, UK, CRC Press Inc, pp. 583-590, 2009.

[2] Walski T., Practical tips for reducing energy use. Proc. of the XI International Conference on Computing and Control for the Water industry, Exeter, 2011.

[3] Shihu S., Dong Z., Suiqing L., Ming Z., Yixing Y. \& Hongbin Z., Power Saving in Water Supply System with Pump Operation Optimization, Proc. of the 2010 Asia-Pacific Power and Energy Engineering Conference (APPEEC), IEEE, Ed., pp. 1-4, 2010.

[4] Puust R., Maddison M. \& Laanearu J., Reviewing the effectiveness of gpu power when used for water network optimization problems. Proc. of the XI 
International Conference on Computing and Control for the Water Industry, Exeter, 2011.

[5] Gonçalves F.V. \& Ramos H.M., Energy optimization and micro-hydro solution in wss: a case study. Proc. of the XI International Conference on Computing and Control for the Water Industry, Exeter, 2011.

[6] Souza E.V., Covas D.I.V. \& Soares A.K., Methods for improving the efficiency in the use of water resources and energy in water supply systems. Proc. of the XI International Conference on Computing and Control for the Water Industry, Exeter, 2011.

[7] Ramos H. M., Mello M. \& De P.K., Clean power in water supply systems as a sustainable solution: from planning to practical implementation, Water Science \& Technology: Water Supply-WSTWS, 6, pp. 39-49, 2010.

[8] Gomez J.B., Proyecto de Planta desalinizadora de agua de mar. Las Palmas de Gran Canaria, July 1988.

[9] Biedrzycka A., Langer. A., Zielona energia w Wodociągach Krakowskich. Nowoczesne Budownictwo Inżynieryjne, 6, pp. 28-31, 2012.

[10] Ramos H.M., Borga A. \& Simão M., New design solutions for low-power energy production in water pipe systems Water Science and Engineering, 2(4), pp.69-84, 2009.

[11] Ferrante M., Todini E., Massari C., Brunone B. \& Meniconi S., Experimental investigation of the leak hydraulics. Proc. of the XI International Conference on Computing and Control for the Water Industry, Exeter, 2011.

[12] Mehzad N., Tabesh M., Hashemi S.S. \& Kia B.A., Reliability of pumping station in water distribution networks considering VSP and SSP. Proc. of the XI International Conference on Computing and Control for the Water industry, Exeter, 2011.

[13] Walski T., Bezts W., Posluszny E. \& Weir M., Modeling leakage reduction: through pressure control. Journal of American Water Works Association, 98(4), pp. 147-155, 2006.

[14] Gold Coast Water, Final Independent Report for the Pressure and Leakage Management Project for Department of Environment, Water, Heritage and the Arts. October 2009.

[15] Polish patent application P-402369, 28.01.2013.

[16] Polish patent application P-410376, 04.12.2014.

[17] Polish patent application P-402370, 28.01.2013.

[18] Polish patent P-395698, 25.09.2013

[19] Polish patent P-395697, 25.09.2013 